\title{
A Comparison of Laryngeal Mask Airway-Supreme (LMAs) and Endotracheal Tube (ETT) as Airway Device in Adult Patients Undergoing Laparoscopic Surgery
}

\author{
Dr. Vaishali Chandrashekhar Shelgaonkar ${ }^{1 *}$, Dr. Medha Akhilesh Sangawar ${ }^{2}$, Dr. Vishal B Taur ${ }^{3}$ \\ ${ }^{1}$ Professor Indira Gandhi Government Medical College Anaesthesiology Nagpur Maharashtra India \\ ${ }^{2}$ Assistant Professor Indira Gandhi Government Medical College Anaesthesiology Nagpur Maharashtra India \\ ${ }^{3}$ Senior Resident Indira Gandhi Government Medical College Anaesthesiology Nagpur Maharashtra India \\ *Corresponding Author \\ Dr. Vaishali Chandrashekhar Shelgaonkar
}

\section{Article History}

Received: 26.07.2020

Accepted: 03.08.2020

Published: 20.09 .2020

\begin{abstract}
Background and objective: The Laryngeal Mask Airway-Supreme is a single-use supraglottic airway device that offers gastric access. The present study compares the safety and efficacy of LMA Supreme with Endotracheal tube (ETT) in adult patients undergoing laparoscopic procedures. Methods: In this prospective study eighty patients of either sex, ASA grade I \& II, were randomly assigned to LMA-Supreme and ETT for airway management and intraoperative ventilation. After induction of general anesthesia, devices were inserted, correct placement was verified, airway leak was noted, and a gastric tube was inserted. Insertion success rates and time, ventilatory capability, efficacy of seal, risk of gastric distension and hemodynamic responses were investigated. Results: The insertion of LMA-S was comparatively easier and required lesser time for insertion than ETT.Ventilation parameters and airway pressure during peritoneal insufflations, for LMA-S and ETT were comparable.LMA-S and ETT show similar efficacy during laparoscopic surgery with controlled ventilation. No gastric distension or signs of regurgitation were detected in both groups. The hemodynamic responses to insertion and removal were greater for the ETT than LMA-S.Complications or pharyngo-laryngeal morbidity was less with LMA-S as compared to ETT. Conclusions: The LMA-S is a safe, efficacious and easy-to-use, supraglottic airway device during general anaesthesia for normal as well as laparoscopic procedure. It provides a functional airway seal with minimum adverse events.
\end{abstract}

Keywords: Laryngeal Mask Airway-Supreme (LMA-S), Laparoscopic procedures, airway device, Anaesthesia management.

\section{INTRODUCTION}

The major responsibility of the anaesthesiologist is to provide adequate ventilaion to the patient during anaesthesia that is through the airway. Management of the airway has come a long way since the development of endotracheal intubation by Macewen in 1880 to present day use of modern andsophisticated devices [1]. Tracheal intubation is the most familiar and conventional way to secure an airway. This is considered to be the 'gold standard' for airway management during administration of general anaesthesia and critical care settings to provide positive pressure ventilation. Tracheal intubation is routinely done by direct visualization of vocal cords after laryngoscopy. In case of difficult intubation it may not be possible to visualize the cords after laryngoscopy [2]. In spite of a plethora of intubating aids and difficult airway algorithms [3], failed or difficult tracheal intubation is the most important cause of mortality and morbidity in anaesthesia [4]. With the advent of newer supraglottic airway devices these drawbacks are avoided.

In the preceding few years a number of supraglottic airway devices have been introduced in the clinical practiceof the airway management, trying to offer a simpleand effective alternative to the endotracheal intubation. Newer supraglottic airway devices have modifications to improved seal and to separate the respiratory and the

Copyright @ 2020: This is an open-access article distributed under the terms of the Creative Commons Attribution license which permits unrestricted use, distribution, and reproduction in any medium for non commercial use (NonCommercial, or CC-BY-NC) provided the original author and source are credited. 
gastrointestinaltracts. All of these factors are designed to reducegastric insufflation, regurgitation and subsequent pulmonary aspiration [5].

The LMA Supreme Airway is the leading single-use, second generation gastric access device which forms an effective first seal with the oropharynx and an innovative verifiable second seal with the upper esophageal sphincter. LMA supreme was designed in 2007 to combine the desirable features of ILMA and LMA proseal. It represents the most advanced laryngeal - airway yet developed by Archie Brain. It is made of latex-free medical grade polyvinylchloride (PVC) for single use. The firm elliptical and anatomically shaped airway tube facilitates easy insertion, without placing fingers in the patient's mouth or placing any introducer tool for insertion.Ithas a gastric access using a lubricated gastric tube up tosize $16 \mathrm{~F}[6,7]$. It is designed to channel fluids away from theairway in the unlikely event of active or passiveregurgitation, and allows for diagnostic testing andverifiable positioning.

The present study was planned to compare the LMA-S and ETT as regards insertion success rates and time requirements, ventilation measurements, efficacy of seal, gastric distension and haemodynamic responses, adverse events and postoperative upper airway morbidity in adult patient's undergoinglaparoscopic procedures.

\section{Materials ANd Methods}

This prospective, randomized control trialwas conducted in the department of Anaesthesiology in tertiary care hospital. Before starting the study ethical approval has been obtained from the Hospital Ethical Committee.A written informed consent was obtained from all the patientsafter explaining the procedureposted for various laparoscopic surgeries under general anesthesia.Study included total 80 patients belonging to ASA grade I \& II of either sex with the age and weight between $18-60$ years and $35-70 \mathrm{kgs}$ respectively. Patients were randomly allocated to two groups of 40 each for laryngeal mask airway supreme (LMA-S) and Endotracheal tube (ETT).Patients with predicted difficult airway by history and examination, not consenting, ASA grade III/IV, non NBM, patients at risk of aspiration, pregnant patients, oesophageal pathology, hiatus hernia, obese or morbidly obese, patients with asthma, allergy, psychiatric disorder, seizure disorder, hypertension, coronary artery disease were excluded. A detailed preanaesthetic evaluation including thorough general and systemic examination, liver function tests, urine analysis were obtained in all patients and whenever indicated X-ray chest PA view and ECG were also advised to rule out systemic disease.All patients received overnight medication of oral Famotidine $40 \mathrm{mg}$ and diazepam $10 \mathrm{mg}$ the night before surgery and was fasted after midnight. In thepreoperative room, baseline parameters likepulse rate, systolic and diastolic blood pressure, electrocardiography, respiratory rate and $\mathrm{SpO} 2$ were recorded.After confirming NBM status, all patients were premedicated with ranitidine $50 \mathrm{mg}$ IV midazolam along with glycopyrrolate $0.04 \mathrm{mg}$ IM given 30 minutes before scheduled surgery.10mins before induction in both the groups, topical spraying of oropharyngeal mucosa with $4 \%$ lignocaine was done. Patients were preoxygenated with $100 \% \mathrm{O}_{2}$ for five minutes. 2 mins before inductionmidazolam $0.03 \mathrm{mg} / \mathrm{kg}$ and fentanyl $2 \mathrm{mcg} / \mathrm{kg}$ were administered. Anesthesia was induced with propofol $2 \mathrm{mg} / \mathrm{kg}$ until an adequate depth of anaesthesia (loss of eyelash reflex) was attained and $1.5 \mathrm{mg} / \mathrm{kg}$ succinylcholine was given to facilitate airway device insertion.

In LMA-S group, size 3 LMA-S or size 4 LMA-S was inserted after lubricating the dorsal surface of the device. In the ETT-group, the trachea was intubated with standard endotracheal tube size $-7,7.5,8 \mathrm{~mm}$ for females and size - 8 , $8.5,9 \mathrm{~mm}$ for male as per patient requirement.The cuffs of both devices were inflated with air using aneroid manometer (cuff pressure gauge, VBM)to an intracuff pressure $60 \mathrm{cmH} 2 \mathrm{O}$ (LMA-S) and 25cmH2O (ETT) and maintained at this value throughout the procedure. After connecting to the Bain circuit, lungs were manually ventilated to check for an effective airway. The 12 G for LMA-S-3 and 14 G for LMA-S-4 Ryle's tube were inserted immediately after devices placement.The time taken for correct placement was recorded (picking up the gastric tube until confirmation).Gastric tube placement was not attempted with LMA-S if there was an air leak up the drainage tube. Correct placement was confirmed by air injection and epigastric stethoscopy. Suction was applied to gastric tube and the presence or absence of any gastric content was recorded.The gastric tube was then immediately removed. The insertion time was recorded from removal of the face mask to attachment of the breathing system to the LMA-S or ETT after cuffs inflation. The number of attempts taken to insert the LMA-S and the ETT was recorded.Three attempts were allowed before a failure of insertion was recorded. If the LMA-S couldn't achieve satisfactory airway, ETT was inserted for airway management.The lungs were ventilated with volume controlled mechanical ventilatior via Anaesthesia delivery unit by Heyer (Modular) with a closed circuit incorporating a $\mathrm{CO} 2$ absorber. Ventilatory setting included as inspiratory: expiratory time of $1: 2$, set tidal volume $8 \mathrm{ml} / \mathrm{kg}$. The initial respiratory rate was $12 / \mathrm{min}$ and adjusted to maintain an EtCO2 of upto $40 \mathrm{mmHg}$ using a fresh gas flow of $3 \mathrm{~L} / \mathrm{min}$.

An effective airway was defined as bilateral chest movement and auscultation, normal value of partial pressure of end-tidal carbondioxide (EtCO2), normal capnograph curve [5] and fiberoptic visualization of the glottic opening. Additional tests were performed to ascertain correct placement of LMA-S; pressure leak test for airway sealing pressures, lubricating jelly test and passage of gastric tube. Once an effective airway was obtained, glottic seal airway (or oropharyngeal leak) pressure was measured by closing the expiratory valve of the circle system at a fixed gas flow of 
$3 \mathrm{~L} / \mathrm{min}$. The rising pressure within the system was measured with the pressure gauge and allowed to increase until it stopped rising (glottic seal pressure) or the expiratory valve manually opened when pressure exceeded $40 \mathrm{cmH} 2 \mathrm{O}$ and recorded. The location of gas leak at oropharyngeal leak pressure was determined as audible sound of gas escaping from mouth; audible sound of gas escaping into the oesophagus heard; and bubbling of lubricant placed on the proximal end of the drain tube.The position was assessed fiberoptically, using the grading[22] (Legend 1).

Grade $4=$ only cords seen

Grade $3=$ vocal cords plus posterior epiglottis seen

Grade $2=$ vocal cords plus anterior epiglottis seen

Grade $1=$ cords not seen but functions adequately

Grade $0=$ cords not seen and functions inadequately

Hemodynamic responses ( $\mathrm{HR}$ and MAP), oxygen saturation $\left(\mathrm{SpO}_{2}\right)$ and end-tidal carbon dioxide $\left(\mathrm{EtCO}_{2}\right)$ were recorded at the intervals: pre-induction, pre-insertion of the LMA-S or ETT, post- gastric tube insertion, precarboperitoneum and post-carboperitoneum recorded postoperatively. Anaesthesia was maintained with sevoflurane, oxygen and neuromuscular blockade with intermittent dose of vecuronium $0.1 \mathrm{mg} / \mathrm{kg} / \mathrm{hr}$.

Carboperitoneum was established by introduction of Veres needle in the abdominal cavity and desired intra abdominal pressure $(15 \mathrm{mmHg})$ was set manually and the electronic variable flow insufflators, which terminates flow automatically when a preset intra abdominal pressure is reached. There was continuous display of intra abdominal pressure and the volume of $\mathrm{CO} 2$ insufflated on the monitor of the insufflator.

At the end of the procedure, reversal of neuromuscular blockade was achieved with $0.05 \mathrm{mg} / \mathrm{kg}$ neostigmine and $0.01 \mathrm{mg} / \mathrm{kg}$ glycopyyrolate. LMA-S was removed with minimally inflated cuff when patient follows verbal commands.Similarly patient was extubated in ETT group.

The main outcome measures were insertion characteristics of LMA-S or ETT and gastric tube. The incidence of regurgitation, aspiration, bronchospasm, desaturation, trauma and postoperative airway morbidity was noted. Hemodynamic responses, $\mathrm{SPO}_{2}$ and $\mathrm{EtCO}_{2}$ were also recorded at various intervals (minor outcomes). Data for respiratory variables and change in stomach size were analyzed. Each surgeon scored the size of the stomach as an ordinal scale of $(0-10)$, at initial insertion of the laparoscope and immediately before its removal.

\section{Statistical Analysis}

The software used in the analysis was SPSS 17.0 and Graph Pad Prism 5.0. All the data expressed as means \pm standard deviation or number and percentage as appropriate. Statistical analysis was done by using descriptive and inferential statistics using chisquare test and z-test. . $P$-Value $<0.05$ is considered as level of significance.

\section{RESULTS}

Demographic data and type of surgeries was depicted in Table 1. There was no failure in placement of both airway devices and a crossover between groups. LMA-S was correctly placed on the first attempt in 38 of 40 patients. Tracheal intubation was successful on the first attempt in 34 of 40 patients. The effective airway time for LMA-S and ETT were $27.60 \pm 5.11$ and $44.02 \pm 5.35$ seconds respectively $(\mathrm{p}<0.0001)$ (Table 1$)$. Ventilation parameters and airway pressures were comparable at all intervals between both study groups (Figur e3). Differences in ventilation measurements of $\mathrm{EtCO}_{2}, \mathrm{SPO}_{2}$ and Peak airway pressure between LMA-S and ETT groups were not statistically significant (Fig 1, 2 and 3). $\mathrm{SpO}_{2}$ changes were in normal ranges and none of the patient had desaturated in either of the study groups.

The peak airway pressure during any phase of surgery was always lesser than the oropharyngeal leak pressure $(18-27 \mathrm{cmH} 2 \mathrm{O})$ in LMA-S group. Fiber optic airway position (Grades = 4/3/2/1) was in $28(70 \%) / 6(15 \%) / 6(15 \%) / 0$ patients respectively for the LMA-S group patients (Figure no.4). In ETT group, HR and MAP increased significantly just after intubation where as in LMA-S group, there were no significant rise in the HR and MAP after removal of the device. (Figure 5 and 6).The stress response during insertion /intubation and removal/ extubation was significantly obtunded in LMA-S group.There was no significant gastric distension in either of the study groups. Thus there is no risk of gastric insufflation with LMA-S.

Complications or pharyngo-laryngeal morbidity were noted in the form of sore throat, dysphagia, dysphonia (hoarseness). Patient in LMA-S group had significantly lower pharyngo-laryngeal complications than the ETT group.No case of regurgitation, aspiration, and desaturation was seen in either of the study groups. 
Table-1: Demographic data, type of surgeries and insertion characteristics of LMA-S and ETT

\begin{tabular}{|l|l|l|l|}
\hline Variable & LMA-S & ETT & P Value \\
\hline Age (yr) & $27.92+/-6.01$ & $28.37+/-5.76$ & 0.99 \\
\hline Gender (M:F) & $19: 21$ & $20: 20$ & 0.82 \\
\hline Weight (kg) & $51.65+/-7.85$ & $52.42+/-7.96$ & 0.99 \\
\hline Surgery type: & & & \\
-Lap Cholecystectomy & $9(22.5 \%)$ & $10(25 \%)$ & \\
-Lap Appendectomy & $14(35 \%)$ & $9(22.5 \%)$ & \\
-Diagnostic Laparoscopy & $6(15 \%)$ & $7(17.5 \%)$ & 0.66 \\
-Lap Hernioplasty & $11(27.5 \%)$ & $14(35 \%)$ & \\
\hline Insertion Attempts (1/2/3) & $38 / 2 / 0$ & $34 / 5 / 1$ & 0.28 \\
\hline Effective Airway Time & $27.60 \pm 5.11$ & $44.02 \pm 5.35$ & $\mathrm{P}<0.0001$ \\
\hline
\end{tabular}

Table-2: Ventilation variable in both the groups

\begin{tabular}{|l|c|c|c|c|c|c|}
\hline \multirow{2}{*}{ Time Interval } & \multicolumn{3}{|c|}{ EtCO2 $(\mathbf{m m H g})$} & \multicolumn{2}{c|}{ Peak Airway Pressure (cmH2O) } \\
\cline { 2 - 7 } & LMA $-\mathrm{S}$ & ETT & p-value & LMA - S & ETT & p-value \\
\hline Just After Insertion & $28.95 \pm 1.29$ & $28.42 \pm 2.01$ & 0.17 & $15.40 \pm 1.08$ & $15.10 \pm 1.78$ & 0.36 \\
\hline 5 min & $30.42 \pm 1.48$ & $30.40 \pm 1.95$ & 0.40 & $16.52 \pm 1.03$ & $16.15 \pm 1.67$ & 0.23 \\
\hline 10 min & $36.12 \pm 1.74$ & $35.37 \pm 2.32$ & 0.10 & $23.30 \pm 2.06$ & $22.60 \pm 1.75$ & 0.10 \\
\hline Mean Intraoperative & $36.02 \pm 2.14$ & $35.35 \pm 1.99$ & 0.14 & $20.30 \pm 2.48$ & $20.10 \pm 1.80$ & 0.68 \\
\hline
\end{tabular}

(Mean \pm standard deviation)

Table-3: Variation of SpO2 (mmHg) in both the groups

\begin{tabular}{|c|c|c|c|}
\hline Time Interval & $\begin{array}{c}\text { LMA }- \text { S } \\
\text { Group }\end{array}$ & $\begin{array}{c}\text { ETT } \\
\text { Group }\end{array}$ & p-value \\
\hline Pre Op & $99.30 \pm 0.68$ & $99.32 \pm 0.65$ & 0.868 \\
\hline After Premedication & $99.30 \pm 0.75$ & $99.30 \pm 0.72$ & 1.000 \\
\hline After Induction & $99.32 \pm 0.61$ & $99.25 \pm 0.77$ & 0.633 \\
\hline Just After Insertion & $99.40 \pm 0.67$ & $99.40 \pm 0.74$ & 1.000 \\
\hline 5 min & $99.45 \pm 0.59$ & $99.40 \pm 0.70$ & 0.734 \\
\hline 10 min & $99.52 \pm 0.67$ & $99.50 \pm 0.67$ & 0.870 \\
\hline Mean Intraoperative & $99.55 \pm 0.59$ & $98.52 \pm 1.10$ & 0.861 \\
\hline Post Op & $99.20 \pm 0.64$ & $99.32 \pm 0.47$ & 0.32 \\
\hline
\end{tabular}

(Mean \pm standard deviation)

Table-4: Hemodynamic changes in both the study groups

\begin{tabular}{|c|c|c|c|c|c|c|}
\hline \multirow{2}{*}{ Time Interval } & \multicolumn{3}{|c|}{ HR } & \multicolumn{3}{c|}{ MAP } \\
\cline { 2 - 7 } & LMA -S & ETT & p-value & LMA -S & ETT & p-value \\
\hline Pre Op & $78.28 \pm 11.27$ & $77.72 \pm 10.37$ & 0.829 & $91.32 \pm 9.57$ & $90.50 \pm 9.87$ & 0.706 \\
\hline After Premedication & $74.37 \pm 12.23$ & $70.45 \pm 8.98$ & 0.106 & $84.95 \pm 9.23$ & $85.47 \pm 9.26$ & 0.800 \\
\hline After Induction & $73.32 \pm 12.13$ & $70.60 \pm 8.47$ & 0.248 & $83.10 \pm 8.99$ & $84 \pm 9.04$ & 0.657 \\
\hline Just After Insertion & $73.35 \pm 16.68$ & $80.15 \pm 8.29$ & 0.025 & $83.65 \pm 8.93$ & $90.95 \pm 10.12$ & 0.001 \\
\hline 5 min & $74.67 \pm 12.96$ & $74.55 \pm 8.59$ & 0.960 & $84.77 \pm 8.43$ & $88.30 \pm 9.73$ & 0.087 \\
\hline 10 min & $87.02 \pm 11.51$ & $85.72 \pm 9.42$ & 0.582 & $99.27 \pm 9.46$ & $97.75 \pm 10.00$ & 0.486 \\
\hline Mean Intraoperative & $78.62 \pm 12.35$ & $77.02 \pm 7.39$ & 0.485 & $86.27 \pm 6.44$ & $89.72 \pm 7.04$ & 0.025 \\
\hline Post Op & $81.20 \pm 11.58$ & $86.22 \pm 7.89$ & 0.026 & $89.87 \pm 7.58$ & $99.62 \pm 6.55$ & 0.000 \\
\hline \multicolumn{7}{|c|}{ Mean \pm standard deviation) } \\
\end{tabular}




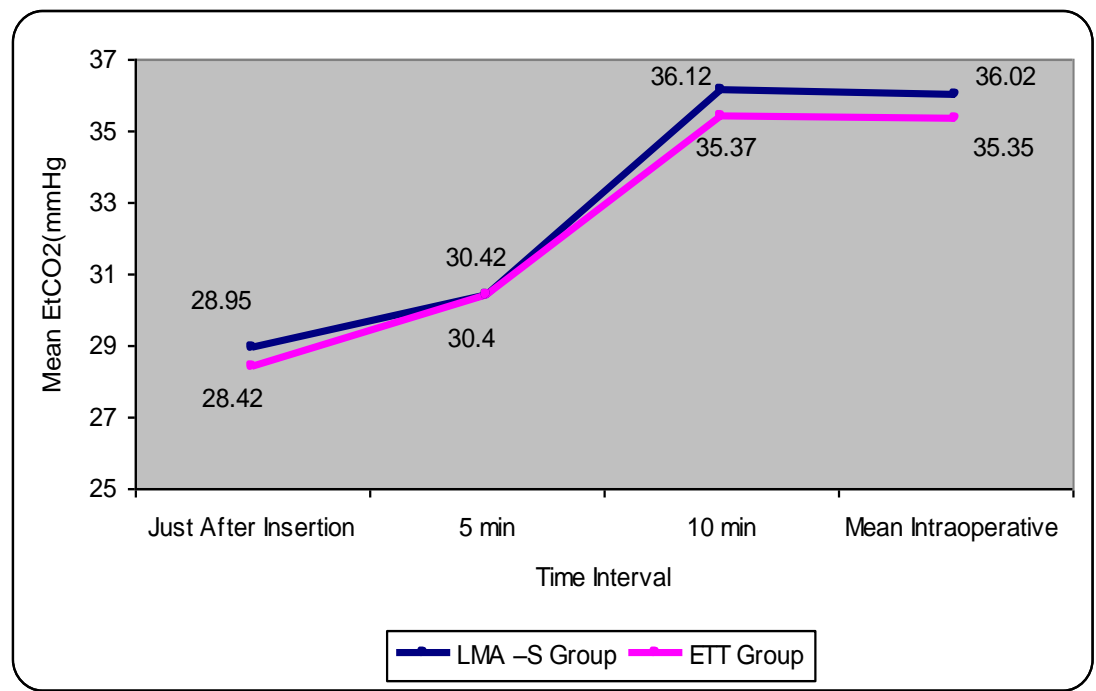

Fig-1: Graphical presentation of EtCO2 $(\mathrm{mmHg})$ between LMA-S and ETT

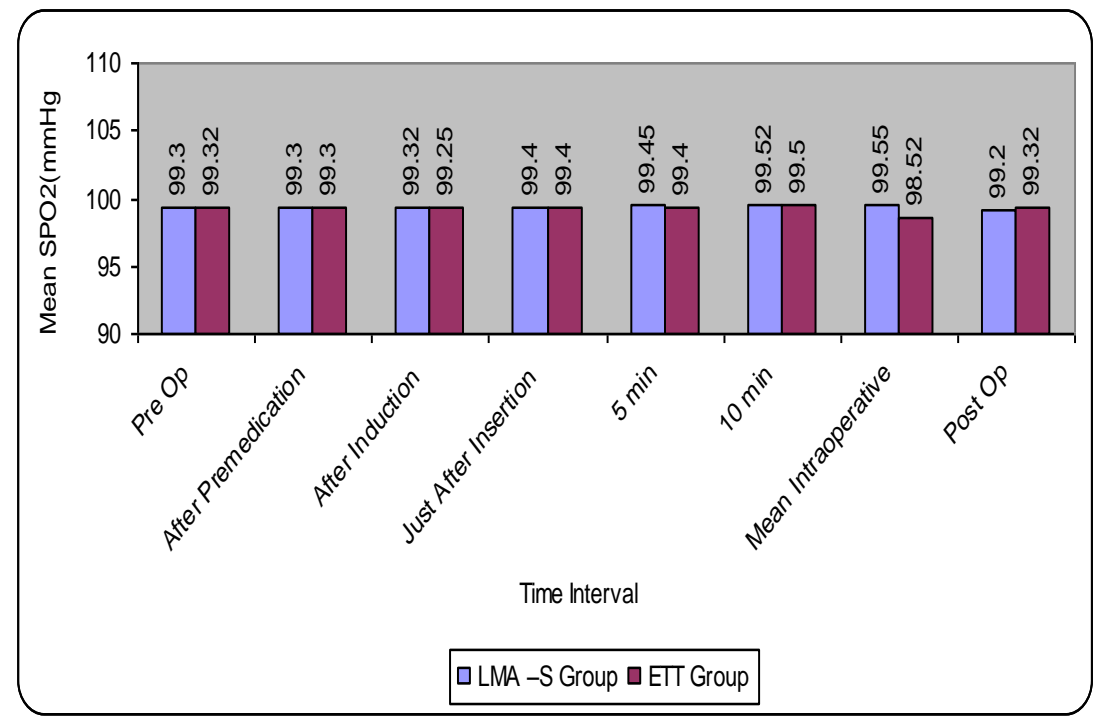

Fig-2: Graphical presentation of SpO2 $(\mathrm{mmHg})$ between LMA-S and ETT

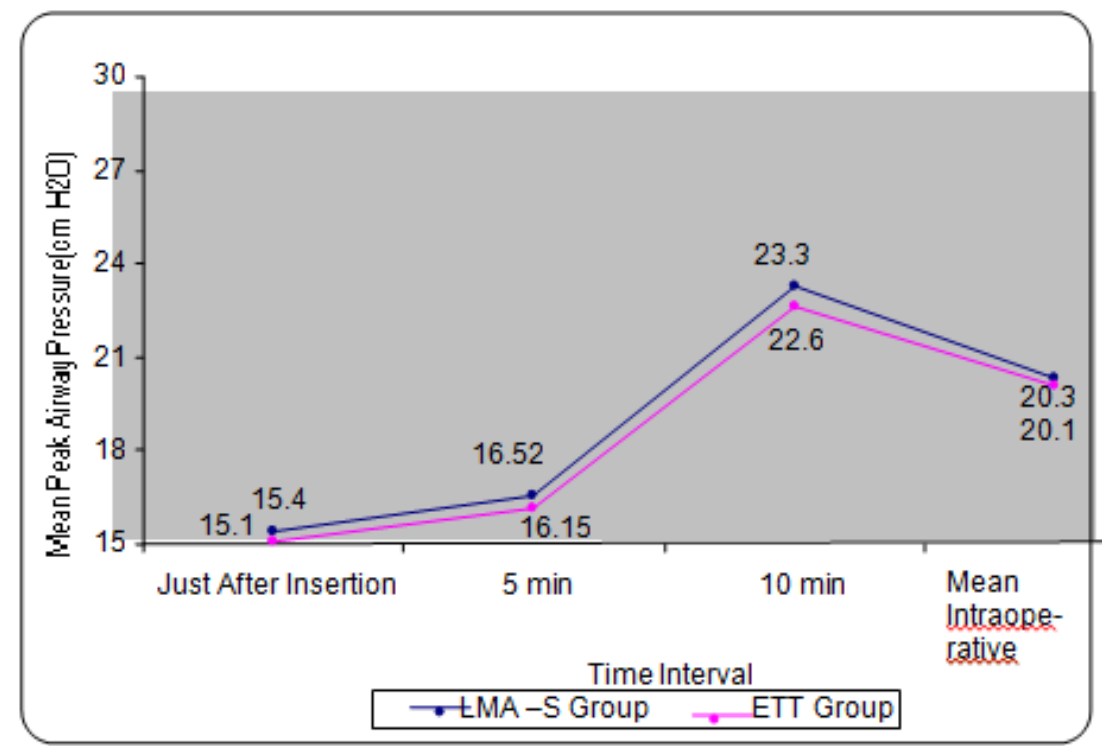

Fig-3: Graphical presentation of Peak Airway Pressure (cmH2O) between LMA-S and ETT 


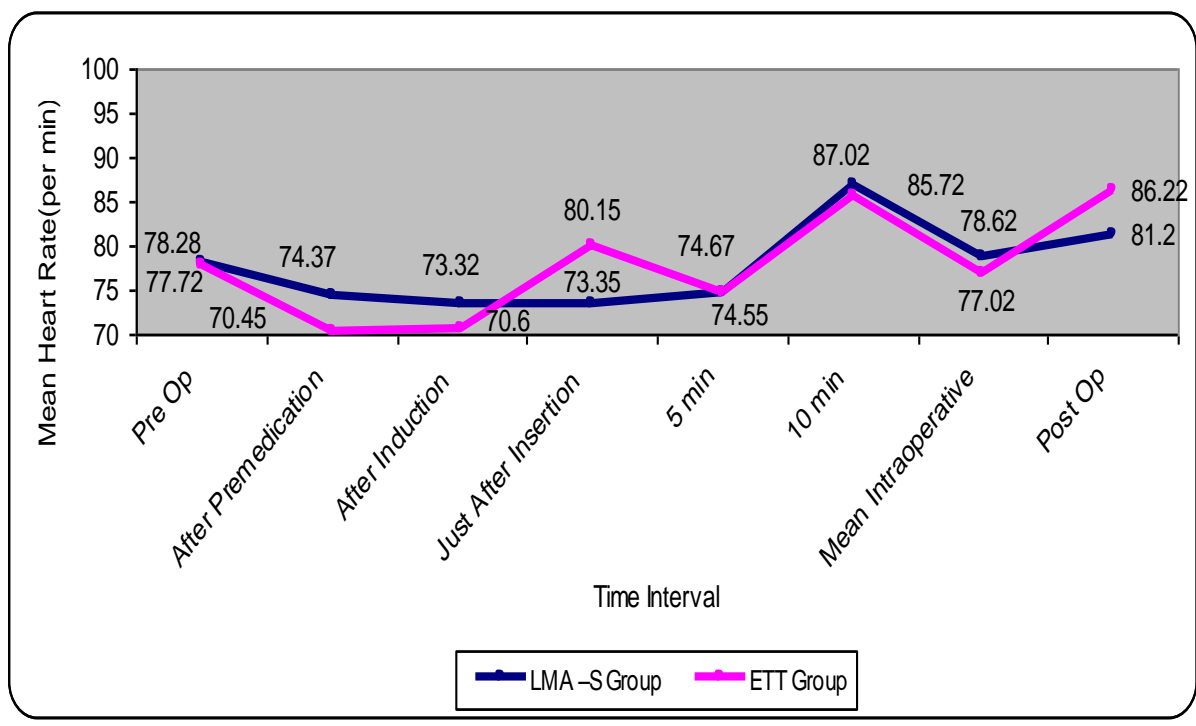

Fig-4: Graphical presentation of Heart Rate in both the groups

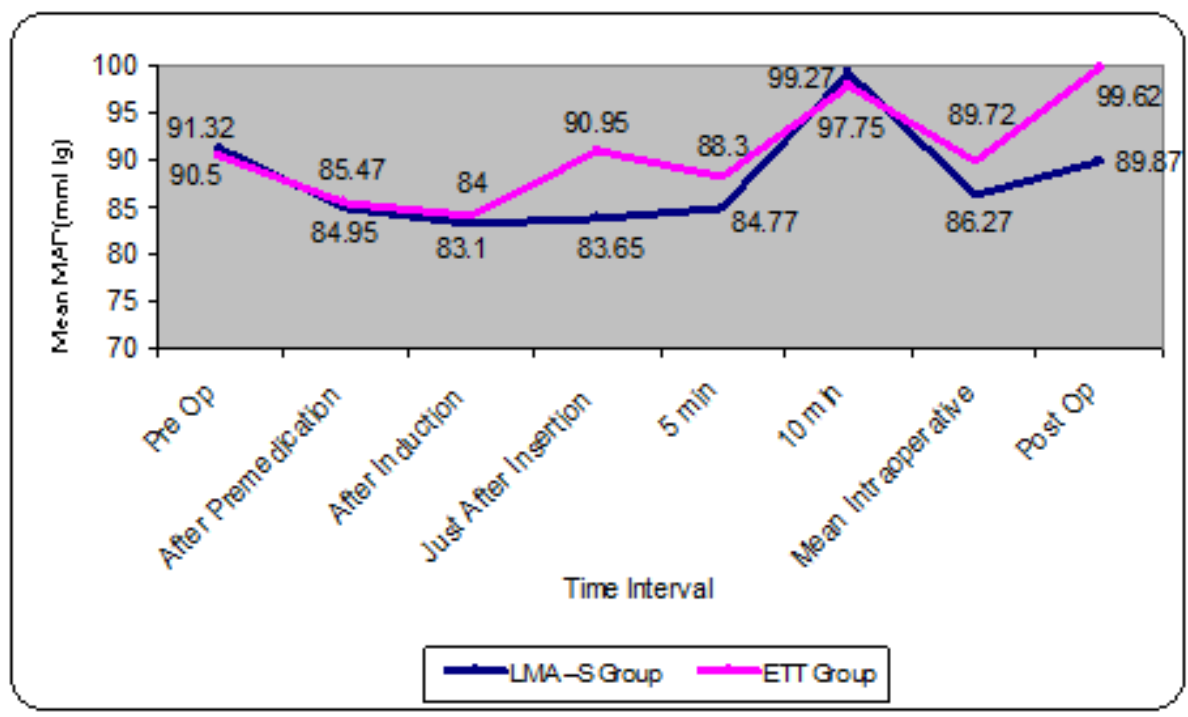

Fig-5: Graphical presentation of MAP in both the groups

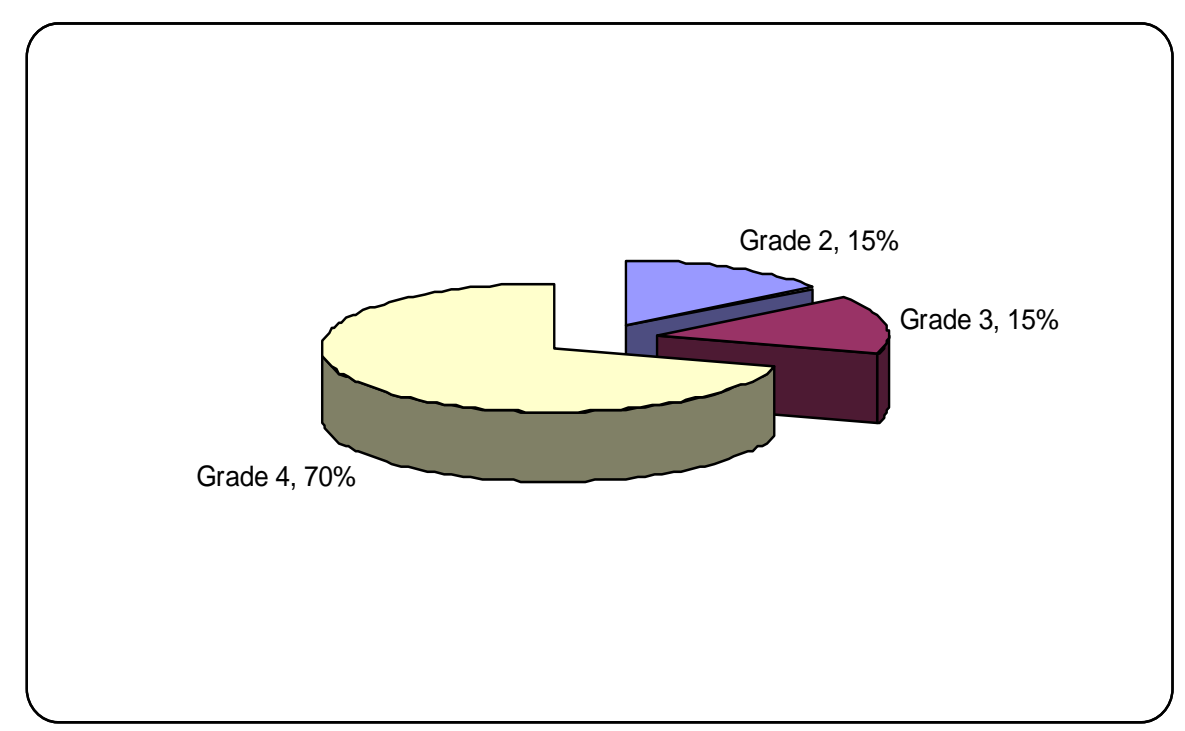

Fig-6: Distribution of patients according to Fiber Optic Grading 


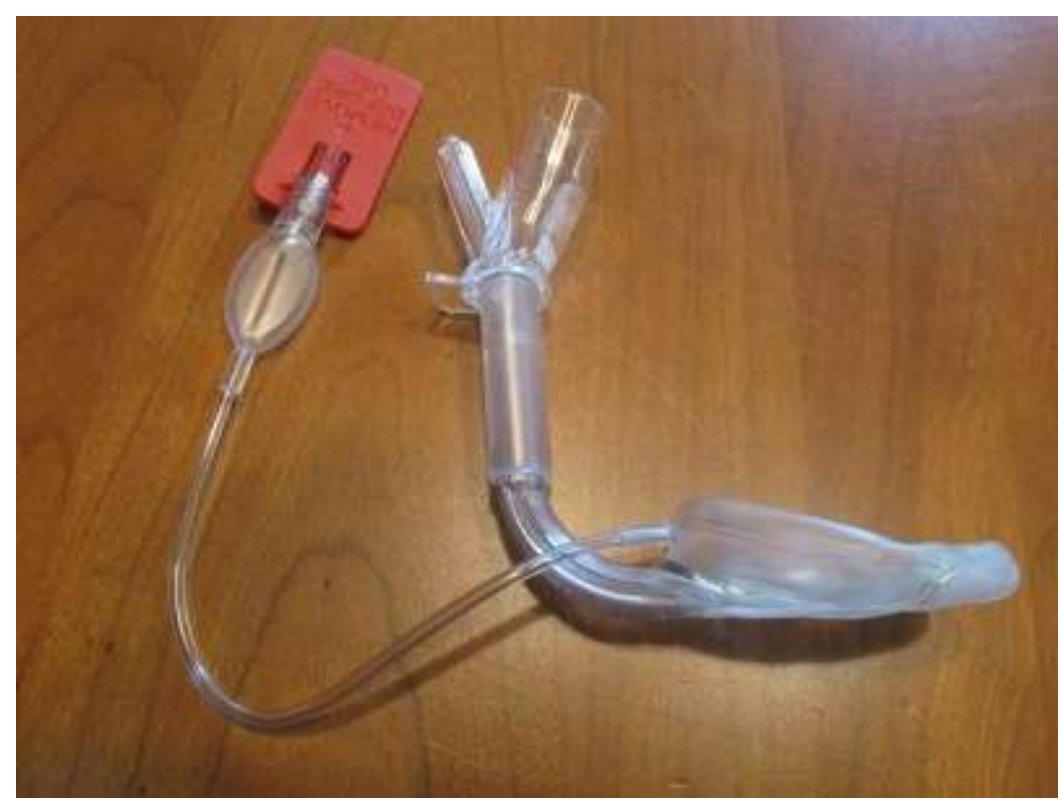

LMA-s (Laryngeal mask airway-Supreme

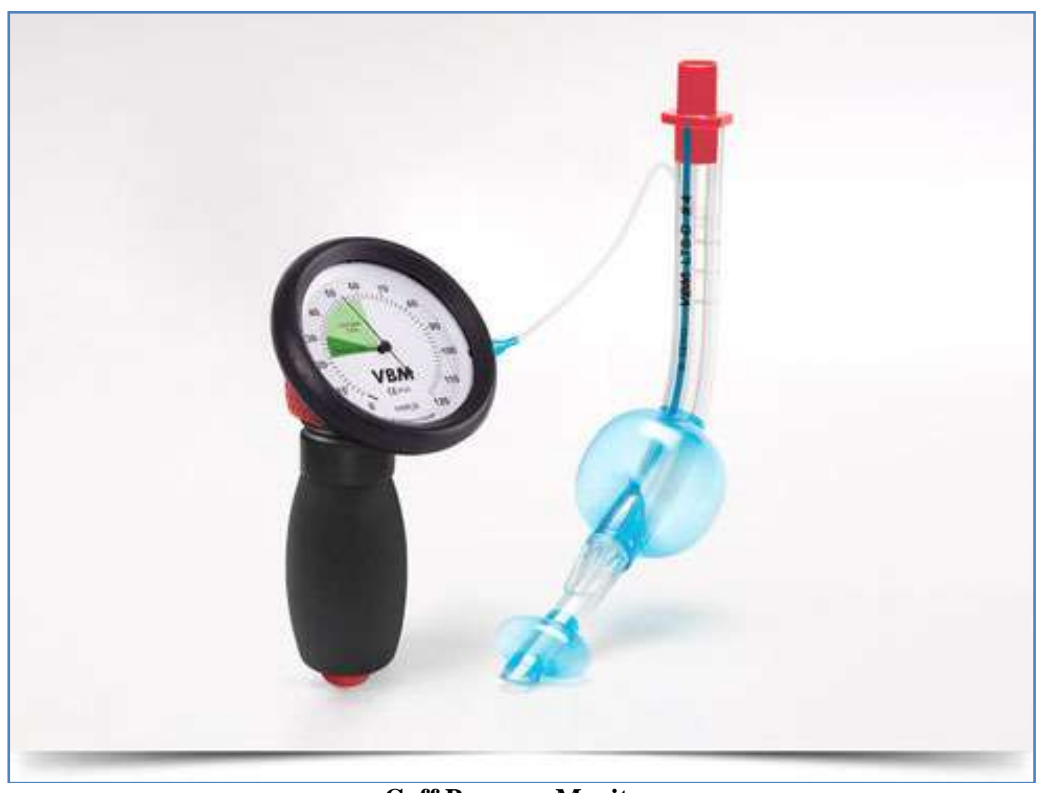

Cuff Pressure Monitor

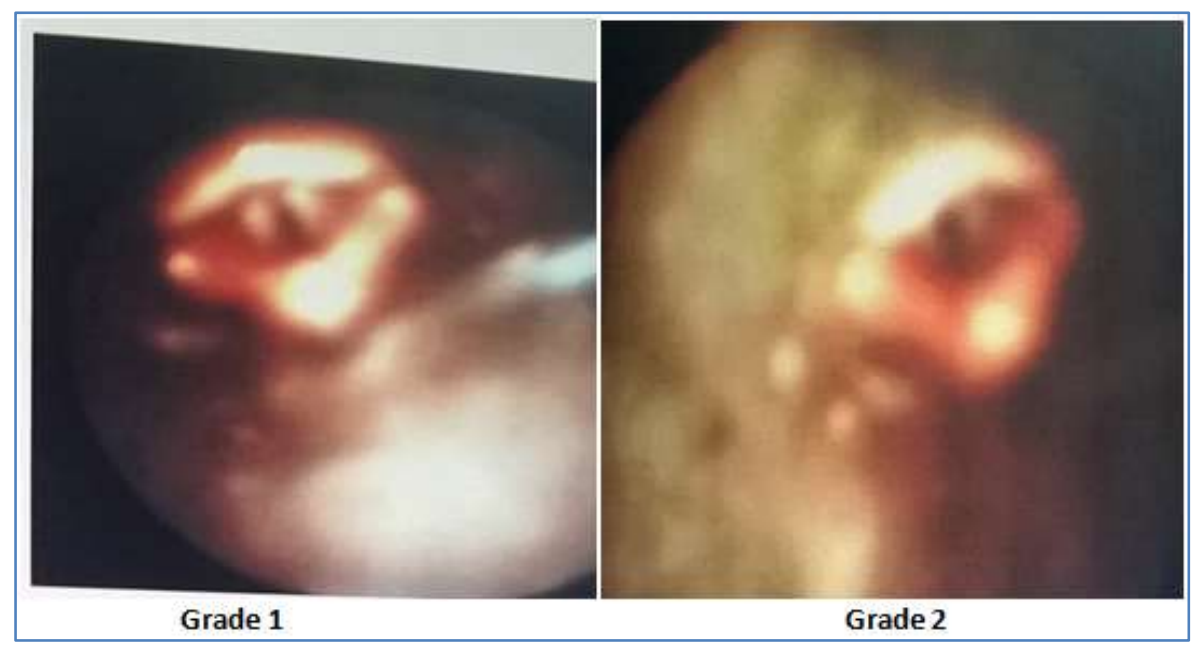




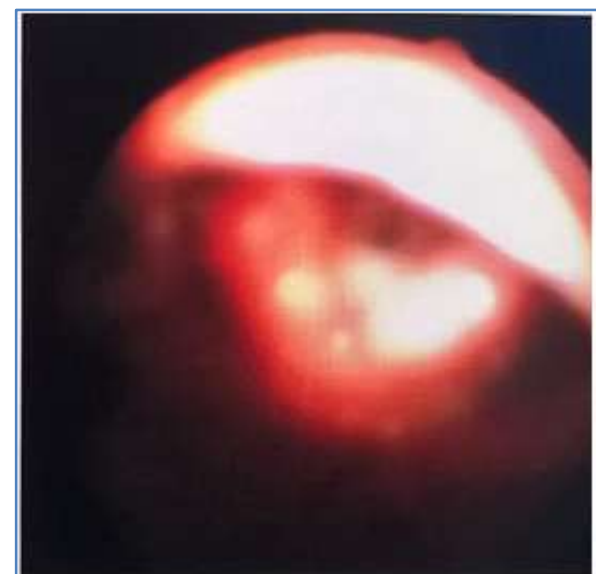

Grade 3

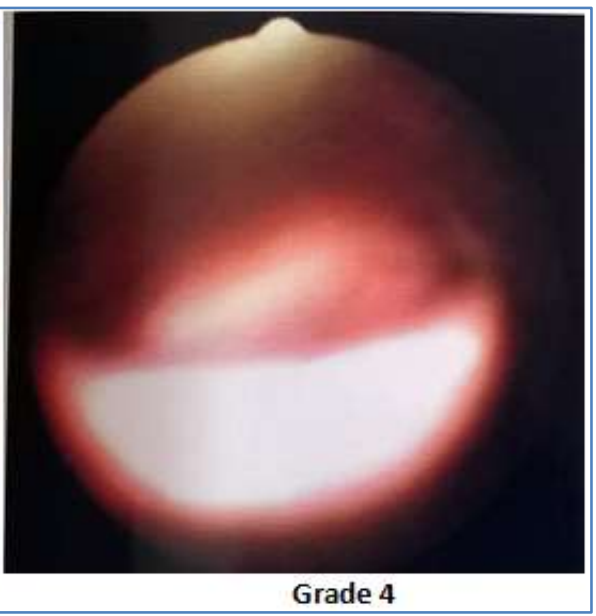

Grade 4

Photographic views of grades of placement of LMA-s via Fiberoptic assessment

\section{DISCUSSION}

The widespread use of supraglottic airway devices has revolutionized some clinical scenarios in modern anaesthetic practice, and on many occasions, are good alternatives to the endotracheal tube [8-10]. Low pulmonary ventilation, gastric distension, and aspiration associatedwith the use of LMA were not more frequent inlaparoscopic surgery than with the use of endotracheal tubes [11]. Viira et al. [12] found thereported aspiration incidence and serious morbidity frequencytogether with LMA to be very low. LMA Supreme is a new airwaydevice for which innovative applications are constantlybeing developed. Numerous studies are increasingly being published about these applications [8-10]. Thus acknowledging the studies of various authors and their favorable result, this prospective randomized study was designedto compare the safety and efficacy of LMA-S and endotracheal tube as airway devicein adult patients posted for laparoscopic surgery, so that it can be used as alternative to endotracheal tube in airway management.

In the present study, success rate of the first attempt insertion and effective airway time was superior in the LMA-S group than theETT group.LMA-S insertion involves less mechanical manipulation of upper airway than ETT. These findings were consistent \& comparable with the findings in various studies $[5,10,13-16]$. These observations can have important implications to Anaesthesiologists and physicians managing patients with supraglottic airway devices. The position of the LMA-S was evaluated after successful insertion and determination of the airway pressures and tidal volumes. The fiberoptic position of the airway tube (LMA-S) was determined by passing a fiberoptic scope (3.7mm diameter) through the main channel of airway tube (LMA-S) to a position $1 \mathrm{~cm}$ proximal to the end of the tube using a self sealing adapter which prevents disconnection and doesn't interfere with conduct of anaesthesia. ${ }^{17} \mathrm{We}$ found no difference in adequacy of ventilation despite poor view on fiberoptic assessment as shown by various ventilatory parameters. Thus with respect to fiberoptic view grading our findings were comparable to various studies by different authors $[5,13,16,22]$.

The marked increase in EtCO2 at 10 mins time interval after insertion /intubation can be explained by the carboperitoneum created during laparoscopy in both the group at that particular time, also rise was within normal limits and ventilation was not compromised at any point during entire surgical procedure.Mullet et al. found that EtCO2 and pulmonary $\mathrm{CO} 2$ elimination increased between the eight and tenth min regardless of site and duration of insufflations [18]. No case of desaturation was seen in either of the group, thus ventilation was adequate in both groups at all intervals throughout the surgery. Significant rise in peak airway pressure in both the groups was noted at 10 min interval which corresponds to $\mathrm{CO} 2$ insufflation time. This was found to be statistically significant $(\mathrm{p}<0.05)$ could be explained by the raised intra abdominal pressure created by $\mathrm{CO} 2$ insufflation at a persistence pressure of about $15 \mathrm{mmHg}$, leading to cephalad displacement of diaphragm.

We found no evidence of regurgitation /aspiration in any of the groups as indicated by ventilatory parameters values and safe $\mathrm{SpO} 2$ and EtCO2 values.The airway sealing pressure or the oropharyngeal leak test is commonly performed to quantify the seal with theairway when a LMA is used. This has been commonlyused as a model in LMA studies to denote the successful placement of the airway [19]. Furthermore, the leak pressureis important to indicate the success of positivepressure ventilation and the degree of airway protection [20]. In our study oropharyngeal leak pressure was found in the range 18 to $27 \mathrm{cmH}_{2} \mathrm{O}$ and in any case peak airway pressure during any phase of laparoscopic surgery was lesser than oropharyngeal leak pressure. Thus oropharyngeal leak pressure was at par with various studies providing adequate ventilation and eliminating risk of aspiration. 
The significant rise in HR as well as MAP postoperatively, after extubation in ETT group. i.e.stress response of extubation whereas no significant rise was noted in LMA-S group after insertion of the device, $(\mathrm{p}<0.05)$. We found no any significant gastric distension in either of the study groups. Gastric insufflations if any was also monitored in this study $[21,13]$. The bronchospasm was seen in 3 patients and stridor was noted in 2 patients of ETT group. No such case of either bronchospasm or stridor was found in LMA-S group. Regurgitation, aspiration, desaturation was not seen in any of the study groups.In our study in ETT group $17.5 \%$ patients had sore throat, $25 \%$ patients had dysphonia and $7.5 \%$ had dysphagia. Thus we can say that the incidence of pharyngo-laryngeal morbidity is decreased when LMA-S is used as airway device.Our findings were in accordance to various studies comparing the incidence of complications in LMA-S group $[9,13,15,16]$.

LMA-S and ETT show similar efficacy during laparoscopic surgery under general anaesthesia with controlled ventilation. LMA-S insertion is quicker and aids easy insertion of the gastric tube with minimal complications and stable haemodynamics responses [9].

\section{CONCLUSION}

The study concludedthat LMA-S is efficacious as an airway device during general anaesthesia for normal as well as laparoscopic procedure. Thus it may offer a reliable and significant airway management option owing to its higher airway pressure afforded, and its separation of alimentary and respiratory tracts. Also using LMA-S instead of a "goldstandard" ETT allows reduction in the postoperative pharyngo -laryngeal morbidity resulting from airway management.

\section{Clinical Significance}

The untoward effects and complications of use of ETT, as it requires instrumentation i.e. laryngoscopy of the upper airway thereby leading to concomitant haemodynamic responses (manifesting as hypertension and tachycardia), damage to oropharyngeal structure at insertion, difficult intubation and failed intubation can be eliminated with the use of LMAs providing equally effective pulmonary ventilation without clinically significant gastric distension in all non-obese patients and during laparoscopic procedures too.

\section{ACKNOWLEDGEMENT}

We are thankful to Institutional Ethical Committee for their concern regarding approval of this study and also to colleagues in Surgery and Anaesthesiology Department.

\section{REFERENCES}

1. James, C. D. T. (1974). Sir William Macewen and anaesthesia. Anaesthesia, 29(6), 743-753.

2. Samsoon, G. L. T., \& Young, J. R. B. (1987). Difficult tracheal intubation: a retrospective study. Anaesthesia, 42(5), 487-490.

3. Biebuyck, J. F., \& Benumof, J. L. (1991). Management of the difficult adult airway with special emphasis on awake tracheal intubation. Anesthesiology: The Journal of the American Society of Anesthesiologists, 75(6), 10871110.

4. Caplan, R. A., Posner, K. L., Ward, R. J., \& Cheney, F. W. (1990). Adverse respiratory events in anesthesia: a closed claims analysis. Anesthesiology: The Journal of the American Society of Anesthesiologists, 72(5), 828-833.

5. Cook, T. M., Lee, G., \& Nolan, J. P. (2005). The ProSeal ${ }^{\mathrm{TM}}$ laryngeal mask airway: a review of the literature. Canadian Journal of Anesthesia, 52(7), 739.

6. Verghese, C., Ramaswamy, B. (2008). LMA-Supreme-a new single-use LMA with gastric access: a report on its clinical efficacy. Br JAnaesth, 101:405-10.

7. Seet, E., Rajeev, S., Firoz, T., Yousaf, F., Wong, J., Wong, D. T., \& Chung, F. (2010). Safety and efficacy of laryngeal mask airway Supreme versus laryngeal mask airway ProSeal: a randomized controlled trial. European Journal of Anaesthesiology (EJA), 27(7), 602-607.

8. Lee, A. K. Y., Tey, J. B. L., Lim, Y., \& Sia, A. T. H. (2009). Comparison of the single-use LMA supreme with the reusable ProSeal LMA for anaesthesia in gynaecological laparoscopic surgery. Anaesthesia and intensive care, 37(5), 815-819.

9. Abdi, W., Amathieu, R., Adhoum, A., Poncelet, C., Slavov, V., Kamoun, W., \& Dhonneur, G. (2010). Sparing the larynx during gynecological laparoscopy: a randomized trial comparing the LMA Supreme ${ }^{\mathrm{TM}}$ and the ETT. Acta Anaesthesiologica Scandinavica, 54(2), 141-146.

10. Yao, T., Yang, X. L., Zhang, F., Li, N., DU, H., Wang, D. X., \& Wu, X. M. (2010). The feasibility of Supreme laryngeal mask airway in gynecological laparoscopy surgery. Zhonghua yi xue za zhi, 90(29), 2048-2051. 
11. Ozdamar, D., Güvenç, B. H., Toker, K., Solak, M., \& Ekingen, G. (2010). Comparison of the effect of LMA and ETT on ventilation and intragastric pressure in pediatric laparoscopic procedures. Minerva anestesiologica, 76(8), 592.

12. Viira, D., \& Myles, P. S. (2004). The use of the laryngeal mask in gynaecological laparoscopy. Anaesthesia and intensive care, 32(4), 560-563.

13. Subramanian, S., \& Sethi, D. (2016). Supraglottic devices in laparoscopic surgery-a review of literature. $J$ Anesth Clin Care, 3, 013.

14. Teoh, W. H. L., Lee, K. M., Suhitharan, T., Yahaya, Z., Teo, M. M., \& Sia, A. T. H. (2010). Comparison of the LMA Supreme vs the i- gel ${ }^{\mathrm{TM}}$ in paralysed patients undergoing gynaecological laparoscopic surgery with controlled ventilation. Anaesthesia, 65(12), 1173-1179.

15. Seet, E., Rajeev, S., Firoz, T., Yousaf, F., Wong, J., Wong, D. T., \& Chung, F. (2010). Safety and efficacy of laryngeal mask airway Supreme versus laryngeal mask airway ProSeal: a randomized controlled trial. European Journal of Anaesthesiology (EJA), 27(7), 602-607.

16. Russo, S. G., Cremer, S., Galli, T., Eich, C., Bräuer, A., Crozier, T. A., \& Strack, M. (2012). Randomized comparison of the $\mathrm{i}-\mathrm{gel}^{\mathrm{TM}}$, the LMA Supreme ${ }^{\mathrm{TM}}$, and the Laryngeal Tube Suction-D using clinical and fibreoptic assessments in elective patients. BMC anesthesiology, 12(1), 18.

17. Wong, D. T., Yang, J. J., \& Jagannathan, N. (2012). Brief review: the LMA Supreme ${ }^{\mathrm{TM}}$ supraglottic airway. Canadian Journal of Anesthesia/Journal canadien d'anesthésie, 59(5), 483-493.

18. Mullett, C. E., Viale, J. P., Sagnard, P. E., Miellet, C. C., Ruynat, L. G., Counioux, H. C., ... \& Annat, G. J. (1993). Pulmonary CO2 elimination during surgical procedures using intra-or extraperitoneal CO2 insufflation. Anesthesia and analgesia, 76(3), 622-626.

19. Brimacombe, J. R., Brimacombe, J. C., Berry, A. M., Morris, R., Mecklem, D., Clarke, G., ... \& Kirk, T. (1998). A comparison of the laryngeal mask airway and cuffed oropharyngeal airway in anesthetized adult patients. Anesthesia \& Analgesia, 87(1), 147-152.

20. Keller, C., Brimacombe, J. R., Keller, K., \& Morris, R. (1999). Comparison of four methods for assessing airway sealing pressure with the laryngeal mask airway in adult patients. British journal of anaesthesia, 82(2), 286-287.

21. Maltby, J. R., Beriault, M. T., Watson, N. C., Liepert, D., \& Fick, G. H. (2002). The LMA-ProSealTM is an effective alternative to tracheal intubation for laparoscopic cholecystectomy. Canadian Journal of Anesthesia, 49(8), 857-862.

22. Keller, C., Brimacombe, J., \& Puehringer, F. (2000). A fibreoptic scoring system to assess the position of laryngeal mask airway devices. Interobserver variability and a comparison between the standard, flexible and intubating laryngeal mask airways. AINS-Anästhesiologie. Intensivmedizin. Notfallmedizin. Schmerztherapie, 35(11), 692-694. 